\title{
WYBRANE ZAGADNIENIA WPROWADZAJĄCE W TEMATYKE ATEIZMU
}

\section{Wstęp}

Ateizm uważa się za atrakcyjny temat rozważań i dyskusji naukowych ostatniej dekady. Pole zainteresowań studiów nad ateizmem pokrywa się dzisiaj z wieloma dziedzinami badań naukowych, takich jak psychologia, filozofia umysłu, socjologia religii, filozofia, antropologia $i$ wiele innych, a mowa tu tylko o teoretycznym i metodologicznym podejściu do zagadnienia. Mając na uwadze współczesne rozpowszechnienie ateizmu i przystępując do badania tego zjawiska, należałoby sobie postawić pytanie o możliwie najlepszy punkt wyjścia do badań ateizmu jako prądu myślowego i zjawiska społecznego. Prof. Jan Woleński - jeden z czołowych przedstawicieli współczesnej filozofii w Polsce, a zarazem ateista - powiedział, że już na poziomie szkoły średniej należałoby zapoznawać młodzież z podstawowymi założeniami ateizmu. Jako lekturę obowiązkową zalecił wydaną $\mathrm{w}$ środowisku oksfordzkim książkę współczesnego filozofa, Juliana Bagginiego, Atheism: A Short Introduction ${ }^{1}$. Gdy prześledzi się z kolei wypowiedzi Bagginiego, można odnaleźć jego rekomendacje dotyczące książek o fundamentalnym znaczeniu dla badaczy ateizmu². Są to: Dialogi o religii naturalnej. Naturalna historia religii Davida Hume'a ${ }^{3}$, Egzystencjalizm jest humanizmem Jeana Paula Sartre'a ${ }^{4}$, Western Atheism: Short History Jamesa Throwera ${ }^{5}$, Odczarowanie Daniela Dennetta ${ }^{6}$ oraz Atheism: The Origin of the Species Nicka Spencera ${ }^{7}$. Warto dołączyć do tej listy jeszcze Boga urojonego Richarda Dawkinsa ${ }^{8}$, Historię ateizmu Georgesa Minoisa ${ }^{9}$, Ateizm Andrzeja Rusłana

Zob. J. Baggini, Atheism: A Very Short Introduction, Oxford 2003.

2 Zob. J. Baggini, The best books on Atheism, fivebooks.com/best-books/julian-baggini-on-atheism [dostęp: 6 X 2020 r.].

3 Zob. D. Hume, Dialogi o religii naturalnej. Naturalna historia religii, thum. A. Hochfeldowa, Warszawa 1962.

4 Zob. J.P. Sartre, Egzystencjalizm jest humanizmem, thum. J. Krajewski, Warszawa 1998.

5 Zob. J. Thrower, Western Atheism: Short History, [b.m.w.] 1999.

6 Zob. D. Dennett, Odczarowanie. Religia jako zjawisko naturalne, thum. B. Stanosz, Warszawa 2006.

7 Zob. N. Spencer, Atheism: The Origin of the Species, London-Oxford 2014.

8 Zob. R. Dawkins, Bóg urojony, thum. P. Szwajcer, Warszawa 2007.

9 Zob. G. Minois, Historia ateizmu. Niewierzący w świecie zachodnim od jego początku do naszych czasów, tłum. W. Klenczon, Warszawa 2019. 
Nowickiego ${ }^{10}$ oraz program An Introduction to Atheism, Secularity and Science, opisany w 2015 r. w czasopiśmie „Science, Religion and Culture”, na który w tej pracy zwraca się szczególną uwagę.

Opracowanie choćby tylko wymienionych tu książek mogłoby stanowić przedmiot wielu opracowań lub nawet sporych rozmiarów pracy naukowej. Celem tego artykułu jest raczej przyjrzenie się temu, czy w przebadanej literaturze mogącej stanowić swoiste wprowadzenie do ateizmu powtarzają się podobne zagadnienia. Już na wstępie można zaznaczyć, że odpowiedź na postawiony wyżej problem jest twierdząca, powinna też znaleźć uzasadnienie w treści artykułu. Zostaną tu bowiem wskazane i pokrótce opisane przynajmniej trzy powtarzające się w większości przeczytanych opracowań zagadnienia: problemy terminologiczne, wpływ ateizmu na psychikę podmiotu i na społeczność, w której funkcjonuje, oraz stosunek ateistów do wiary religijnej i treści jej przekonań.

\section{Uwagi terminologiczne}

Już na samym początku w podejściu do omawianego tu zagadnienia praktycznie we wszystkich przebadanych tekstach na czoło wysuwa się znaczenie pojęcia ateizmu. I już na wstępie należałoby poczynić przynajmniej dwa spostrzeżenia. Po pierwsze, tacy autorzy, jak Thomas Coleman, Ralph Hood i John Shook zauważają obecne współcześnie w literaturze przedmiotu rozróżnienie ateizmu jako stanowiska nazwanego roboczo „teoretycznym” (ang. atheism) oraz ateizmu, jak go nazwano, „praktycznego" (ang. secularism) ${ }^{11}$. Można śmiało się zgodzić z tym rozróżnieniem, zaznaczając, że znane ono było na gruncie filozofii chrześcijańskiej i teodycei już dużo wcześniej, a dwa wyróżnione i wymienione tu podejścia bywały określane jako „ateizm teoretyczny” i ,ateizm praktyczny”" ${ }^{2}$. Pierwszy z nich oznacza raczej pogląd naukowy, stanowisko filozoficzne bądź światopoglądowe ${ }^{13}$. W tym przypadku proponuje się tu ujęcie go w uproszczeniu jako taki sposób wyjaśniania rzeczywistości, a ściślej mówiąc: wszystkiego, co jawi się w strumieniu świadomości podmiotu jako przedmiot poznania, który wyklucza działanie, a tym samym także istnienie jakiegokolwiek czynnika nadprzyrodzonego rozumianego w takim sensie, w jakim pojmują go religie. Jak stwierdza Terence Eagleton, wielu współczesnych ateistów zapewne nie zgodziłoby się z terminem „wykluczenie” obecnym w tej roboczej definicji. Łatwiejsze do przyjęcia byłoby stwierdzenie, że nie wykluczając $\mathrm{z}$ góry istnienia czynników nadprzyrodzonych $\mathrm{w}$ ich religijnym rozumieniu, nie przyjmuje się ich istnienia i działania z braku przekonujących dowodów owej

10 Zob. A.R. Nowicki, Ateizm, Warszawa 1964.

11 T. Coleman, R. Hood, J. Shook, An Introduction to Atheism, Secularity and Science, ,Science, Religion and Culture" 2 (2015), nr 3, s. 1.

12 S. Kowalczyk, Filozofia Boga, Lublin 2001, s. 20.

13 S. Kowalczyk, Podstawy światopoglądu chrześcijańskiego, Wrocław 1985, s. 8. 
obecności i aktywności ${ }^{14}$. W klasycznym podejściu teoriopoznawczym taka postawa nosiłaby miano sceptycyzmu ${ }^{15}$. Postawa ta - jak zaznaczył Mieczysław Albert Krępiec - nie pozwalałaby podmiotowi zatrzymać się na niej ${ }^{16}$. Drugi z wyróżnionych tu poglądów należałoby nazwać sekularyzmem lub świeckością. Polega on na dokonywaniu różnorakich wyborów życiowych bez uwzględniania przesłanek religijnych, ale także bez szczególnej wrogości wobec nich. Oczywiście, jak wolno mniemać, na określenie opisanej postawy życiowej i moralnej chętniej stosuje się nazwę ,neutralność światopoglądowa” lub inne o podobnym polu semantycznym. Jeśli chodzi o drugie spostrzeżenie, to należy zauważyć, że myśliciele stojący na stanowisku ateizmu nie preferują traktowania ich poglądów w punkcie wyjścia jako przeciwstawienia teizmowi i religii. Starają się usilnie, aby ateizmu nie postrzegano jako cienia światopoglądu religijnego. Chodzi o to, aby nie sugerując się prefiksem terminu ,a-teizm”, traktować ten pogląd jako w istocie pozytywny, a nie jedynie permanentnie zaprzeczający poglądom religijnym ${ }^{17}$. Istnieją także takie rozróżnienia, w których sekularyzm traktuje się jako odrzucanie pewnych przekonań religijnych zarówno na płaszczyźnie teoretycznej, jak i praktycznej, ateizm zaś jako odrzucanie pewnych specyficznych twierdzeń teologicznych, i to w znaczeniu takim, że za ateistę uznaje się każdego, kto nie przyjął jeszcze żadnej konkretnej wersji teizmu ${ }^{18}$. Po zasygnalizowaniu spostrzeżeń związanych z nazwą „ateizm” można przejść do refleksji nad badaniem zachowania ludzkiego w kontekście wiary religijnej lub jej braku.

Współcześnie w podejściu badawczym za cel stawia się unikanie jakichkolwiek założeń oraz redukcyjną definiowalność wszystkich terminów psychologicznych (a za takowy uznaje się wiarę, religię itp.) za pomocą terminów odnoszących się do zjawisk obserwowalnych ${ }^{19}$. W takim razie dla samego zdefiniowania zjawisk, które kryją się pod anglojęzycznymi nazwami non-religion, secularity albo non-belief, należałoby sukcesywnie powtarzać stawiane w duchu wittgensteinowskim pytanie o rozumienie tych terminów przez podmioty, za każdym razem rzucając na nie światło dostarczane przez najnowsze badania lub dowody. Dla przykładu należy zacząć od konkretnego przypadku ludzkiego działania. Niech będzie to akt zapalenia świeczki w ciemnym pokoju. Jeśli nie podano szerszego kontekstu owego pojedynczego zdarzenia, to trudno orzec, czy miało ono charakter religijny, czy nie.

14 T. Eagleton, Rozum, wiara i rewolucja. Refleksje nad debata o Bogu, thum. W. Usakiewicz, Kraków 2010, s. 135-136.

15 Pogląd ten opiera się na starożytnej zasadzie izostenii, która oznacza początkową „równosilność” wszystkich przeciwnych sobie sądów. S. Judycki, Sceptycyzm i dowód ontologiczny, „Analiza i Egzystencja” 11 (2005), nr 1, s. 11.

16 M.A. Krąpiec, Elementy filozofii poznania, w: Wprowadzenie do filozofii, red. M.A. Krąpiec $\mathrm{i}$ in., Lublin 2012, s. 380.

17 J. Baggini, Atheism ..., dz. cyt., s. 92-93.

18 T. Coleman, R. Hood, J. Shook, An Introduction ..., art. cyt., s. 2.

19 J. Bremer, Wprowadzenie do filozofii umystu, Kraków 2010, s. 100. 
Mogło być np. przygotowaniem do medytacji nad słowem Bożym, próbą wywołania ducha bądź po prostu rozjaśnieniem pokoju, żeby znaleźć bezpieczniki i uruchomić na nowo elektryczność. W każdym razie według badaczy reprezentujących najpopularniejszy dziś kierunek filozoficzny, czyli filozofię umysłu (ang. cognitive science), nie istnieją zachowania, które można by nazwać pierwotnie religijnymi. Po przeanalizowaniu współczesnej literatury dotyczącej badania religii metodami filozofii umysłu do takiego wniosku doszedł Jonathan Jong w swoim artykule On (not) defining (non) religion' co znaczy mniej więcej $O$ (nie)definiowalności (nie)religii ${ }^{20}$. Podobne spostrzeżenie poczynił Ethan Quillen w swoim tekście Discourse Analysis and the Definition of Atheism, czyli Dyskursywna analiza i definicja ateizmu. Stwierdził on mianowicie, że ateizm sam w sobie, jako pojęcie, może być nazwą syntetycznie pustą ${ }^{21}$. Oczywiście nie przekreśla to istnienia konkretnych przykładów ateizmu jako światopoglądu poszczególnych osób. Chcąc zatem zdefiniować ateizm in concreto, należałoby przebadać odpowiednią grupę osób deklarujących się jako ateiści i stwierdzić, jak oni sami postrzegają swój własny desygnat terminu ,ateizm” ${ }^{22}$. Ponieważ zdaniem autorów jedyną rzetelną metodą badania zjawisk wiary i niewiary jest metoda nauk społecznych, należałoby zaproponować konkretne sposoby konstruowania ankiet i mierzenia tych zjawisk.

Ogólny wniosek, do jakiego dochodzi się najczęściej w tekstach stanowiących wprowadzenia do ateizmu, brzmi tak, że nie da się do końca określić, czym są lub czym nie są szeroko rozumiane zjawiska niewiary, nieteizmu itp. Aby jednak nie podważać osiągnięć poszczególnych autorów, należałoby powiedzieć, że ich dociekania polegają raczej na poszukiwaniu zespołu kontekstu, w świetle którego można by uznać stosowanie omawianych tu terminów za znaczące dla precyzacji ich za$\mathrm{kresu}^{23}$. Oczywiście to samo per analogiam można powiedzieć o religii. Konkluzja ta nie jest żadnym nowym odkryciem, ponieważ już choćby w środowisku filozofii religii KUL obecnie przyjmuje się, że religia jako taka nie istnieje, jakkolwiek jej nazwa nie jest sprzeczna, a więc podobnie jak w przypadku ateizmu jest ona nazwą - można powiedzieć - syntetycznie pustą, ergo nigdy nie ma się do czynienia z religią w ogólności, a zawsze tylko z konkretnym przykładem konkretnej religiii ${ }^{24}$. $\mathrm{Ci}$ zatem, którzy dowodzą nieistnienia „ateistów w ogólności”, dowodzą także nieistnienia „ludzi religijnych w ogólności”. Podobnie ma się sprawa z istnieniem desy-

20 J. Jong, On (not)defining (non) religion, ,Science, Religion and Culture” 2 (2015), nr 3, s. 22.

${ }^{21}$ Jest to nazwa w swojej treści niesprzeczna, lecz realnie nie odpowiada jej ani jeden konkretny przedmiot. Taka byłaby np. nazwa „król Sandomierza”.

22 E. Quillen, Discourse Analysis and the Definition of Atheism, „Science, Religion and Culture" 2 (2015), nr 3, s. 32.

23 E. Quillen, Discourse Analysis..., art. cyt., s. 33.

24 P. Moskal, Religia i prawda, Lublin 2008, s. 26-27. 
gnatów pojęć abstrakcyjnych czy gatunkowych, ale tym zagadnieniem zajmowano się już szeroko w ramach znanego w filozofii sporu o uniwersalia ${ }^{25}$.

\section{Akt wierzenia jako czynnik psychiczno-społeczny}

Oprócz problemów z definicją wiary i niewiary tudzież religijności i niereligijności ważne wydaje się zagadnienie punktu wyjścia do badań nad religią i ateizmem, a mianowicie samego aktu wierzenia. Powszechnie uznaje się pozytywy bycia osobą wierzącą. Dowiedziono wszakże, a zgadzają się z tym również ateiści, że wierzenie jest dobre nawet dla psychicznego i fizycznego zdrowia podmiotu ${ }^{26}$. Oczywiście w tym miejscu można postawić pytanie, czy wierzenie absolutnie we wszystko oraz każdy rodzaj wierzenia są faktycznie dobre. Według Luke’a Williama Galena i Jamesa Kloeta badania poświęcone niejako świeckim cnotom, jak altruizm, pokora, pozytywne emocje, szczęście itp., których zespół można by najogólniej nazwać dobrostanem (ang. well-being), dowodzą występowania tych cnót zależnie od poziomu religijności człowieka. Dzieje się tak rzekomo dlatego, że prowadzi się tzw. eksperymenty krzyżowe, w których badani łączą w sobie żądane cechy z wysokim poziomem religijności i wiary. Niemniej jednak w sposób nieuprawniony wysuwa się wniosek głoszący, że brak wiary i religijności automatycznie skutkuje brakiem tychże pozytywnych wartości. Po prostu pomija się badanie dobrostanu niewierzących w celu dowiedzenia dobrostanu wierzących i wzajemnej korelacji tego pozytywnego uczucia $\mathrm{z}$ wiarą ${ }^{27}$. Natomiast na temat pozytywnego wpływu wiary na stan sumienia i zachowanie jednostki interesujące spostrzeżenia poczynił Justin McBrayer, analizując na nowo znany z filozofii ,zakład Pascala” w artykule The Wager Renewed: Believing in God is Good for You doszedł do wniosku o korzyściach płynących z przyjęcia tezy teistycznej ${ }^{28}$. McBrayer zarzucił Pascalowi podejście czysto pragmatyczne i znalazł dwa problemy w wywodzie filozofa. Po pierwsze, nie bierze on rzekomo pod uwagę, że rozważanie świata „z Bogiem” i „bez Boga” jest w istocie rozważaniem dwóch różnych światów, w których zupełnie inaczej przedstawiają się korzyści hedonistyczne. Po drugie, jeśliby przyjąć, że „Bóg Pascala” jest tym samym Bogiem, którego można poznać z chrześcijańskiego katechizmu, to należałoby podać w wątpliwość nagradzanie wierzących za wiarę nie motywowaną miłością do Boga, lecz chęcią

${ }^{25}$ M.A. Krąpiec, Elementy filozofii poznania ..., dz. cyt., s. 388-389.

${ }^{26}$ Z. Zdybicka, Człowiek i religia, w: Wprowadzenie do filozofii, dz. cyt., s. 483.

${ }^{27}$ L.W. Galen, J. Kloet, Mental Well-Being in the Religious and the Non-Religious: Evidence for a Curvilinear Relationship, „Mental Health, Religion \& Culture” 14 (2010), nr 7, s. 674.

28 Blaise Pascal nie opisał explicite swojego rozumowania jako argumentu przemawiającego za istnieniem Boga. Rozważanie znane pod nazwą „zakład Pascala” przybliżył w dobie nowożytnej jeden z twórców filozofii pragmatyzmu, William James. Zob. W. James, The Will to Believe and Other Essays in Popular Philosophy, Londyn 1912. 
uzyskania wiecznego zbawienia ${ }^{29}$. Oczywiście pomija się tutaj fakt, że ,zakład Pascala" nie stanowi ścisłego dowodu na istnienie Boga, a raczej sposób na przekonanie niewierzących, że warto założyć, iż żyje się w świecie, w którym Bóg istnieje. Zamiast omawianego tu filozoficznego eksperymentu myślowego McBrayer proponuje przyjęcie wiary w Boga z powodu jej pozytywnego wpływu na ludzkie życie, argumentując, że większość ludzi znajduje uzasadnione powody do wiary w Boga bez dowodów na Jego istnienie. Zgadza się z tym autor Baggini ${ }^{30}$. Do badania wpływu wiary na dobrostan człowieka przystąpił także Galen. Odpowiadając generalnie pozytywnie na pytanie o wartość wiary dla zdrowia psychicznego, postawił on kolejne pytanie, jak i w co dany podmiot wierzy. Doszedł jednak do wniosku, że pozytywne efekty przynosi nie tyle religijna treść tego, w co się wierzy, ile spójność światopoglądu oraz możliwość dzielenia go z innymi podmiotami o podobnych zapatrywaniach ${ }^{31}$. W przeważającej mierze dla ateistów treść przekonań i wiary nie ma tu nic do rzeczy, do tego stopnia, że nie jest istotne, czy człowiek ,układa się z diabłem, Bogiem czy plasterkiem żółtego sera, byleby robił to szczerze i dzielił to przekonanie z innymi” ${ }^{32}$.

Następną rzeczą jest przynależność niewierzących do zorganizowanych grup wolnomyślicielskich. Ateiści uznają za pozytywne zjawisko powstawania bardzo wielu lokalnych grup tego typu, co wydaje się świadectwem cieszącego ateistów faktu zawędrowania tego prądu niejako pod strzechy. Choć w myśl twierdzeń dwudziestowiecznych ateistów pogląd ten sprowadzał zawsze na jednostkę trudności i prześladowania ${ }^{33}$, to jednak dzisiaj - jak ujęli to badacze: Joseph Langston, Joseph Hammer i Ryan Cragun - cel, dla którego powstają grupy wolnomyślicieli zrzeszające ateistów, to „living one's life comfortably without religious belief”, co się tłumaczy: „żyć sobie wygodnie bez przekonań religijnych"34. Już na pierwszy rzut oka cel ten spełnia kryteria utylitarystyczne, a wręcz hedonistyczne.

Można się także pokusić o przeanalizowanie danych liczbowych dotyczących ateistów i osób niewierzących. Większość autorów zarówno ateistów, jak wierzących przystaje na to, że koniec wieku XX i początek XXI nie są dobrym czasem na badania liczbowe. Zauważa się bowiem nieznaczny wzrost zainteresowania religią, coraz głośniej mówi się o czekającej świat odnowie wiary. Tym samym wzrostu liczby osób niewierzących zarejestrowanego w drugiej połowie XX w. nie można uznać za początek ogarniającej cały świat ateizacji, a raczej za zjawisko lokalne. Ci zatem, którzy twierdziliby, że nadchodzi nowa era niewiary, wygłaszaliby twierdzenia

29 J. McBrayer, The Wager Renewed: Believing in God is Good for You, „Science, Religion and Culture" 1 (2014), nr 3, s. 133-134.

30 J. Baggini, Atheism ..., dz. cyt., s. 93.

31 L.W. Galen, Does Religious Belief Promote Prosociality? A Critical Examination, „Psychological Bulletin" 138 (2012), nr 5, s. 876-906.

32 T. Coleman, R. Hood, J. Shook, An Introduction ..., art. cyt., s. 4.

33 A.R. Nowicki, Ateizm, dz. cyt., s. 67-68.

34 J. Langston, J. Hammer, R. Cragun, Atheism Looking in: On the Goals and Strategies of Organized Nonbelief, „Science, Religion and Culture” 2 (2015), nr 3, s. 83. 
przedwczesne. W każdym razie w 2015 r. 26 proc. przebadanej ludności świata (bez udziału Chin) deklarowała się jako niewierzący lub osoby niereligijne. Natomiast po uwzględnieniu przebadanej ludność Chinto odsetek ten wzrasta do 44 proc. Mimo wzrostu liczby ochrzczonych w skali świata, a także odnotowania sporej liczby nawróceń, są to dane bardzo niepokojące dla strony wierzącej ${ }^{35}$. W omawianym tu artykule autorzy stwierdzili, że do 2042 r. odsetek niewierzących, ateistów, agnostyków i ludzi niezwiązanych z żadną religią będzie wynosił w Stanach Zjednoczonych około 40 proc. Zauważają jednak, że za powiększenie niereligijnej części społeczeństwa nie odpowiada bezpośrednio żadna pojedyncza kontrowersja ani kryzys, lecz jest to część szerokiego trendu ogólnej sekularyzacji, inaczej mówiąc - zeświecczenia ${ }^{36}$. Prognostyki te opierają się na założeniu przyjmującym istnienie samonapędzających się mechanizmów religijnych rzekomo obecnych w świadomości człowieka. Julian Baggini, powołując się na badania Russella Stannarda opisane w książce The God Experiment, stwierdza, że jeśli religijna część świadomości w którymś momencie nie będzie w stanie uruchomić u poszczególnego człowieka wspomnianych samonapędzających się mechanizmów, to będzie mogła zostać bez kłopotu odrzucona ${ }^{37}$.

Kolejna obserwacja z lubością podkreślana przez ateistów prowadzi do (może zbyt pospiesznych) wniosków, że coraz więcej osób wykształconych wybiera drogę niewiary lub ateizmu. Klasyczni badacze ateistyczni już od czasów oświecenia wiązali ów wzrost z myśleniem systematycznym, analitycznym i krytycznym, rozpowszechnionym w środowiskach naukowych bardziej niż wśród zwykłych ludzi ${ }^{38}$. Poświęca temu uwagę Benjamin Beit-Hallahmi w tekście Explaining the Secularity of Academics: Historical Questions and Psychological Findings. Autor otwarcie oświadcza, że posiadanie wyższego wykształcenia, np. doktoratu, nie jest przyczyną (jak się wyraził: „gwarancją") ateizmu lub niewiary, lecz według niego istnieje związek między poziomem wykształcenia a niewiarą ${ }^{39}$. W świetle tekstów wprowadzających do ateizmu można stwierdzić, że przyczyna tego rzekomego związku jest podwójna oraz spełnia prognozy starożytnych i nowożytnych ateistów. Przede wszystkim jest to rozpowszechniane już od czasów oświecenia twierdzenie głoszące, że wysoka pozycja w świecie naukowym nie pasuje do światopoglądu religijnego, uznanego podówczas za zacofany. Stanowisko to nazwane zostało „efektem oświecenia" (eminence effect $)^{40}$. Poza tym jest to znane w starożytności przeciwstawienie dwóch sposobów rozumienia świata: religijnego i niereligijnego. Już antyczny filozof Ksenofanes zauważył, że osobisty światopogląd prezentowany przez danego człowieka jest niejako projektowany na całą rzeczywistość. $Z$ tego powodu świato-

35 J. Langston, J. Hammer, R. Cragun, Atheism Looking..., art. cyt., s. 72.

36 J. Langston, J. Hammer, R. Cragun, Atheism Looking..., art. cyt., s. 73.

37 J. Baggini, Atheism ..., dz. cyt., s. 93.

38 A.R. Nowicki, Ateizm, dz. cyt., s. 75.

39 B. Beit-Hallahmi, Explaining the Secularity of Academics: Historical Questions and Psychological Findings, ,Science, Religion and Culture” 2 (2015), nr 3, s. 105.

40 A.R. Nowicki, Ateizm, dz. cyt., s. 76. 
pogląd teistyczny znajduje innego rodzaju wyjaśnienie rzeczywistości niż dla przykładu lansowany w środowisku akademickim światopogląd ateistyczny. Co więcej, silne religijnie przekonania niekiedy wykluczają zdaniem ateistów przyjęcie w pewnych newralgicznych kwestiach (choćby społecznych) postawy otwartej, a przez to dostrzegane przez wszystkich wykluczenie osób głęboko religijnych jeszcze się pogłębia, dysproporcja zaś między liczbą osób wykształconych i głęboko religijnych jeszcze bardziej wzrasta ${ }^{41}$. Co więcej, nawet jeśli uczeni uznają istnienie Boga, to ich poglądy także różnią się od religijnych przekonań przeciętnych wyznawców.

Kolejnym zagadnieniem wysuwanym przez ateistów w różnego rodzaju zbiorach zagadnień wprowadzających $w$ ateizm jest wytrwałość $w$ wierze oraz fakt, że wiarę tracą przeważnie ludzie, którzy do tej pory i tak wierzyli słabo. Jeden z czołowych ateistów współczesnych, Daniel Dennett, zauważył, że w przypadku Biblii zachodzą mechanizmy podobne jak w przypadku dobrej literatury. Każdy spotkał się chyba z sytuacją, w której trudno było mu odłożyć na półkę dobrą książkę, w której się rozczytywał. W odniesieniu do Biblii działa to w ten sposób, że ,tę dobrą książkę, którą jest Biblia, jest nawet trudniej odłożyć, szczególnie wtedy kiedy wiąże się to z utratą korzyści, jakie z niej płyną. Dla wielu duchownych, którzy nie znają innego zajęcia ani sposobu życia czy utrzymania dla nich samych ich żon, dzieci i psów, może być naprawdę trudno odłożyć Biblię nawet długo po tym, jak przestali wierzyć. Dodatkowo na ich pozycji społecznej religijnych urzędników opiera się ich życie towarzyskie z większością przyjaciół i znajomych" ${ }^{42}$. Kiedy w religii następuje przewartościowanie zwane przez rabina Paula Shrell-Foxa „deed over creed”"43, odkrywa się, że religijni przywódcy okazują swoisty lęk egzystencjalny, stając się przez to niewierzącymi przywódcami religijnymi, co owocuje przewartościowaniem ich religijności i praktyk rytualnych w kierunku większego zaangażowania w solidarność społeczną ${ }^{44}$. Bez wskazywania konkretnych przykładów tego typu zachowań należałoby zadać sobie pytanie, czy podobne zjawiska nie dzieją się w obrębie różnych istniejących współcześnie religii.

\section{Ateizm a pojęcie Boga}

W następnej kolejności zainteresowanie wywołuje zagadnienie tzw. treści esencjalnej pojęcia Boga. Już w rozważaniach Kartezjusza twierdzenie o istnieniu bądź nieistnieniu Boga składało się z przesłanki esencjalnej i egzystencjalnej. Przesłanka egzystencjalna była przyjęciem lub odrzuceniem faktu istnienia Boga,

${ }^{41}$ J. Baggini, Atheism ..., dz. cyt., s. 76-77.

42 D. Dennett, L. LaScola, Caught in the Pulpit: Leaving Religion Behind, Durham 2015, s. 27.

43 Oznacza to prymat działalności nad wiarą.

44 P. Shrell-Fox, When Rabbis Lose Faith: Twelve Rabbis Tell Their Stories about Their Loss of Belief in God, ,Science, Religion and Culture” 2 (2015), nr 3, s. 141. 
esencjalna zaś była odpowiedzią na pytanie, co się rozumie pod pojęciem Boga ${ }^{45}$. W słynnym dowodzie św. Anzelma można o wiele wcześniej znaleźć rozważania nad tym, co niewierzący bądź ateiści mają na myśli, mówiąc o Bogu ${ }^{46}$. Otóż zdecydowana większość autorów, w tym także ateistów, zgadza się co do faktu, że jakiekolwiek wyobrażenia, wierzenia czy przekonania - bez względu na to, czy mają one inny niż psychiczny ciężar ontyczny, to znaczy bez względu na to, czy są tylko wytworem wyobraźni podmiotu, czy nie - mogą mieć wpływ na ludzkie zachowania. Dla przykładu badane osoby odmawiały spożycia pokarmu (lub mniej chętnie go spożywały), który wyglądem przypominał zwierzęce odchody, natomiast rzucając strzałkami do tarczy przedstawiającej różnorakie obrazy, odmawiały rzucania do wizerunków cenionych przez siebie osób. Choć badani wiedzieli, że nie mają do czynienia z prawdziwymi odchodami zwierząt ani nie ranią rzeczywiście cenionych przez siebie osób, poważnie się opierały przed wykonaniem zadanych czynności. Eksperyment ten dowodzi zdaniem ateistów, że nawet świadomie fałszywe przekonania wywierają wpływ na zachowanie ludzi. Człowiek nie musi uznawać istnienia danego przedmiotu, aby podlegać efektom jego myślowej reprezentacji ${ }^{47}$. Badanie mające na celu stwierdzenie, czy ktoś jest wierzący, czy nie, byłoby analogiczne do badania stwierdzającego, czy dana osoba jest rasistą, czy nie. W tym ostatnim przypadku najczęściej dochodzi do wypierania przekonania o nastawieniu rasistowskim, jednak decydującą rolę odgrywa tu nie samo wyparcie, lecz wpływ wypieranego poglądu na zachowanie jednostki, tak jak się to ma w przypadku krzyczenia do telewizora przez widza podczas meczu piłki nożnej. Tego typu wnioski wysuwa się w obronie wiary i religijności, twierdząc, że wielu ludzi deklarujących się jako niewierzący lub ateiści należałoby nazwać wierzącymi implicite. Na takie dictum ateiści odpowiadają, że gdyby z kolei przebadać pod tym samym kątem ludzi deklarujących się np. jako chrześcijanie, większość z nich okazałaby się implicite poganami, mającymi za przedmiot swojej wiary jakiegoś boga o przeciętnie ludzkich możliwościach oraz IQ oscylującym w granicach między 100 a $120^{48}$.

45 Kartezjusz sformułował dwa dowody na istnienie Boga: dowód z idei Boga oraz dowód ze skutków. Dowód pierwszy jest tożsamy z dowodem ontologicznym św. Anzelma. Drugi zaś opiera się na twierdzeniu, że skutek nie może być doskonalszy od swej przyczyny. Dowód ze skutków jest skonstruowany następująco: myślący umysł posiada ideę Boga jako bytu najdoskonalszego, a więc ideę doskonałą w swej treści, co świadczy o tym, że nie może być ona tworem niedoskonałego umysłu ludzkiego. R. Descartes, Medytacje o pierwszej filozofii, thum. M. i K. Ajdukiewiczowie, Warszawa 1958 (rozważania na temat istnienia Boga występują w medytacji III i V).

46 Anzelm z Canterbury, Proslogion, tłum. L. Kuczyński, w: Anzelm z Canterbury, Monologion. Proslogion, Kęty 2007, s. 203.

47 T. Coleman, R. Hood, J. Shook, An Introduction ..., art. cyt., s. 6.

48 T. Coleman, R. Hood, J. Shook, An Introduction ..., art. cyt., s. 6. 
Bóg był w ciągu wieków postrzegany bardzo różnorodnie: od pojmowania Go jako przynajmniej pośredniej przyczyny wszystkiego, co dzieje się na świecie ${ }^{49}$, poprzez uznawanie za bezpośrednią przyczynę pewnych specyficznych zmian, typu pojawienie się życia na ziemi, aż do skrajnych form postrzegania Boga jako odpowiedzialnego za dosłownie wszystko, włącznie z decyzjami ludzi, których wolność jest jedynie pozorna, jak przyjmuje się głównie w nurtach fideistycznych ${ }^{50}$. Oczywiście przekonania na temat Boga mogą wpływać na życie i działanie wierzących w Niego, jednak pojawia się pytanie o istnienie podobnego wpływu wśród niewierzących. Czy jest możliwe choćby samo przebadanie niewierzących na temat esencjalnej przesłanki sądu o istnieniu Boga? Jeśli już ateiści próbują sobie wyobrazić Boga, w którego nie wierzą, to czy nasuwa im się obraz Boga, który ich umieści w piekle, czy raczej Boga jako istoty kochającej wszystkich? Takie wyobrażenia mogą być dla samego ateizmu niebezpieczne, ponieważ u podmiotu podzielającego je mogą wywoływać bądź to strach, bądź miłość. Z tego względu Kościół katolicki naucza o „poszukujących"51, natomiast klasyk polskiego ateizmu, Andrzej Rusłan Nowicki, potępia takie postawy jako ,półateistyczne” i stwierdza, że nie mają one nic wspólnego z prawdziwym ateizmem ${ }^{52}$. Zagadnieniu temu poświęcono artykuł zatytułowany: How the Non-Religious View the Personality of God in Relation to Themselves autorstwa Igora Mikloušić'a i Justina Lane'a. Po przebadaniu kilkuset osób deklarujących się jako ateiści autorzy stwierdzili, że to, co ateiści myślą o Bogu, zależy od tego, czy sami kiedykolwiek podzielali jakieś religijne przekonania, czy dowiadują się o Bogu z powszechnie dostępnego nauczania o Nim, które głosi się w ramach religii. Okazuje się, że zaliczający się do pierwszej grupy myślą o Bogu zdecydowanie pozytywniej niż zaliczający się do grupy drugiej, którzy postrzegają Go raczej jako istotę okrutną ${ }^{53}$. Ten efekt znano już od dawna i jeszcze Kotarbiński wyjaśniał go przez kontekst, w którym osoby niegdyś wierzące zdobywały wiedzę o Bogu, przeważnie następowało w rodzinach w okresie dzieciństwa i w sprzyjającym otoczeniu lokalnej wspólnoty religijnej ${ }^{54}$. Zdaniem ateistów, którzy od początku stwierdzali ważną rolę kontekstu przekonań religijnych, badania dowiodły, że umie-

49 Anzelm z Canterbury, Monologion, tłum. L. Kuczyński, w: Anzelm z Canterbury, Monologion. Proslogion, dz. cyt., s. 29-31.

50 Z. Zdybicka, Drogi afirmacji Boga, w: Wprowadzenie do filozofii, dz. cyt., s. 410-411.

51 Sobór Watykański II wyraźnie mówi o ludziach, „którzy bez własnej winy w ogóle nie doszli jeszcze do wyraźnego poznania Boga, a usiłują, nie bez łaski Bożej, wieść uczciwe życie”. Sobór Watykański II, Lumen gentium, nr 16, w: Sobór Watykański II, Konstytucje, Dekrety, Deklaracje. Tekst polski, wyd. III, wyd. Pallotinum, Poznań, b.d.w.

52 A.R. Nowicki, Ateizm, dz. cyt., s. 77.

53 I. Mikloušić, J. Lane, How the Non-Religious View the Personality of God in Relation to Themselves, „Studia Humana” 8 (2019), nr 3, s. 40-41.

54 T. Kotarbiński, Przykład indywidualny kształtowania się postawy wolnomyślicielskiej, w: Religia i ja, red. T. Kotarbiński i in., Warszawa 1981. 
jętność wyobrażenia sobie Boga, nawet we wspomnianej wyżej pozytywnej formie, wcale nie jest jednoznaczna z przekonaniem religijnym implicite $^{55}$.

\section{Zakończenie}

Celem tego krótkiego artykułu było przyjrzenie się zagadnieniu, czy w przebadanej przez autora literaturze mogącej stanowić swoiste wprowadzenie do ateizmu nie powtarzają się podobne tematy i problemy. Odpowiedź na sformułowany wyżej problem jest twierdząca, jako że istotnie można zauważyć kilka zagadnień powtarzających się w różnorakich wprowadzeniach do ateizmu. Są to więc przede wszystkich kwestie terminologiczne, po drugie związane $\mathrm{z}$ wiarą religijną i jej znaczeniem w kontekście psychologicznym i społecznym, po trzecie kwestie stosunku osób ateistycznych i niewierzących do treści wiary religijnej, z pojęciem Boga na pierwszym miejscu, a także zagadnienia historyczne. $Z$ powodu obfitości materiału celowo pominięto w niniejszym tekście kwestie historyczne. Mogą one stać się tematem osobnych interesujących opracowań. Pozostałe tematy zostały w powyższym tekście wyłuszczone i pokrótce omówione. Oczywiście nie jest to żadna wyczerpująca analiza, lecz raczej zwrócenie uwagi na to, w jakim kierunku zdąża formułowanie wspomnianych zagadnień w literaturze wprowadzającej w ateizm. Autor wyraża nadzieję, że zaznaczone tu pokrótce zagadnienia doczekają się głębszych analiz porównawczych.

\section{Bibliografia}

\section{Źródła drukowane}

Anzelm z Canterbury, Monologion. Proslogion, thum. L. Kuczyński, Kęty 2007.

Sobór Watykański II, Konstytucje, Dekrety, Deklaracje. Tekst polski, wyd. 3, Poznań, b.d.w.

\section{Opracowania}

Baggini J., Atheism: A Very Short Introduction, Oxford 2003.

Beit-Hallahmi B., Explaining the Secularity of Academics: Historical Questions and Psychological Findings, „Science, Religion and Culture” 2 (2015), nr 3, s. 104 119.

Bremer J., Wprowadzenie do filozofii umystu, Kraków 2010.

Coleman T., Hood R., Shook J., An Introduction to Atheism, Secularity and Science, „Science, Religion and Culture” 2 (2015), nr 3, s. 1-14.

Dennett D., LaScola L., Caught in the Pulpit: Leaving Religion Behind, Durham 2015.

55 A.R. Nowicki, Ateizm, dz. cyt., s. 78; I. Mikloušić, J. Lane, How the Non-Religious..., art. cyt., s. $40-41$. 
Descartes R., Medytacje o pierwszej filozofii, thum. M. i K. Ajdukiewiczowie, Warszawa 1958.

Eagleton T., Rozum, wiara i rewolucja. Refleksje nad debata o Bogu, thum. W. Usakiewicz, Kraków 2010.

Galen L.W., Does Religious Belief Promote Prosociality? A Critical Examination, „Psychological Bulletin” 138 (2012), nr 5, s. 876-906.

Galen L.W., Kloet J., Mental Well-Being in the Religious and the Non-Religious: Evidence for a Curvilinear Relationship, „Mental Health, Religion \& Culture” 14 (2010), nr 7, s. 673-689.

James W., The Will to Believe and Other Essays in Popular Philosophy, Londyn 1912.

Jong J., On (not)defining (non) religion, „Science, Religion and Culture” 2 (2015), nr 3, s. 15-26.

Judycki S., Sceptycyzm i dowód ontologiczny, „Analiza i Egzystencja” 11 (2005), nr 1, s. 9-29.

Kotarbiński T., Przykład indywidualny ksztaltowania się postawy wolnomyślicielskiej, w: Religia i ja, red. T. Kotarbiński i in., Warszawa 1981.

Kowalczyk S., Filozofia Boga, Lublin 2001.

Kowalczyk S., Podstawy światopogladu chrześcijańskiego, Wrocław 1985.

Krąpiec M.A., Elementy filozofii poznania, w: Wprowadzenie do filozofii, red. M.A. Krąpiec i in., Lublin 2012, s. 335-396.

Langston J., Hammer J., Cragun R., Atheism Looking in: On the Goals and Strategies of Organized Nonbelief, „Science, Religion and Culture” 2 (2015), nr 3, s. $70-85$.

McBrayer J., The Wager Renewed: Believing in God is Good for You, „Science, Religion and Culture" 1 (2014), nr 3, s. 130-140.

Mikloušić I., Lane J., How the Non-Religious View the Personality of God in Relation to Themselves, „Studia Humana” 8 (2019), nr 3, s. 39-57.

Moskal P., Religia i prawda, Lublin 2008.

Nowicki A.R., Ateizm, Warszawa 1964.

Quillen E., Discourse Analysis and the Definition of Atheism, „Science, Religion and Culture" 2 (2015), nr 3, s. 27-34.

Shrell-Fox P., When Rabbis Lose Faith: Twelve Rabbis Tell Their Stories about Their Loss of Belief in God, ,Science, Religion and Culture” 2 (2015), nr 3, s. 131-146.

Zdybicka Z., Człowiek i religia, w: Wprowadzenie do filozofii, red. M.A. Krąpiec $\mathrm{i}$ in., Lublin 2012, s. 469-514.

Zdybicka Z., Drogi afirmacji Boga, w: Wprowadzenie do filozofii, red. M.A. Krąpiec i in., Lublin 2012, s. 397-468. 


\section{Streszczenie}

Ateizm uważa się za atrakcyjny temat rozważań i dyskusji naukowych ostatniej dekady. Pole zainteresowań studiów nad ateizmem pokrywa się dzisiaj z wieloma dziedzinami badań naukowych. Mając na uwadze współczesne rozpowszechnienie ateizmu i przystępując do badania tego zagadnienia, należałoby sobie postawić pytanie o możliwie najlepszy punkt wyjścia. Celem tego krótkiego artykułu jest przyjrzenie się temu, czy w przebadanej literaturze nie powtarzają się podobne zagadnienia. Odpowiedź na postawiony wyżej problem jest twierdząca, jako że istotnie można zauważyć kilka tematów powtarzających się w różnorakich wprowadzeniach do ateizmu. Są to więc przede wszystkim zagadnienia terminologiczne, po drugie związane $\mathrm{z}$ wiarą religijną i jej znaczeniem $\mathrm{w}$ kontekście psychologicznym i społecznym, po trzecie kwestie stosunku osób ateistycznych i niewierzących do treści wiary religijnej, a także zagadnienia historyczne. $Z$ powodu obfitości materiału, celowo pominięto $\mathrm{w}$ niniejszym tekście te ostatnie. Pozostałe tematy zostały w powyższym tekście wyłuszczone i pokrótce omówione.

Slowa klucze: ateizm, wprowadzenie, terminologia, ateizm kontra religia, wiara religijna

\section{Selected Issues Introducing the Topic of Atheism}

\section{Summary}

Atheism has been considered an attractive topic of scientific reflection and discussion in the last decade. The field of interest in the study of atheism today overlaps with many areas of scientific research. Having in mind the current prevalence of atheism and when starting to study this issue, one should ask the question about the best possible starting point. The aim of this short article is to look at whether similar issues are recurring in the studied literature. The answer to the problem above is affirmative, as it is indeed possible to notice several themes repeated in various introductions to atheism. These are, first of all, terminological issues, secondly, related to religious faith and its meaning in the psychological and social context, and thirdly, issues of the attitudes of atheists and non-believers to the content of religious faith, as well as historical issues. Due to the abundance of material, the latter have been deliberately omitted from this text. The remaining topics are listed in the above text and discussed briefly.

Key words: atheism, introduction, terminology, atheism vs. religion, religious belief 
